\title{
Phasic Firing Time Locked to Cocaine Self-Infusion and Locomotion: Dissociable Firing Patterns of Single Nucleus Accumbens Neurons in the Rat
}

\author{
Laura L. Peoples, Fred Gee, Racquel Bibi, and Mark O. West \\ Department of Psychology, Rutgers University, New Brunswick, New Jersey 08903
}

The activity of single nucleus accumbens (NAcc) neurons of rats was extracellularly recorded during intravenous cocaine self-administration sessions $(0.7 \mathrm{mg} / \mathrm{kg}$ per infusion, fixed ratio 1). We reported previously that NAcc neurons showed a change, usually a decrease, in firing rate during the first $1 \mathrm{~min}$ after the cocaine-reinforced lever press. This postpress change was followed by a progressive reversal of that change, which began within the first 2 min after the press and was not complete until the last $1 \mathrm{~min}$ before the next lever press (termed the change + progressive reversal firing pattern). In the present study we documented a regular pattern of locomotion that occurred in parallel with the change + progressive reversal firing pattern. This observation suggested that discharges time locked to locomotion may determine the change + progressive reversal firing pattern. However, $55 \%$ of the neurons failed to show firing time locked to locomotion that could have contrib- uted to the change + progressive reversal firing pattern. Moreover, for all neurons, the change + progressive reversal firing pattern was apparent even if the calculation of firing rate excluded all periods of locomotion. The present data showed that the change + progressive reversal firing pattern is not solely attributable to phasic changes in firing time locked to the execution of locomotion. The change + progressive reversal firing pattern closely mirrors changes in drug level and dopamine overflow observed by previous researchers and may thus be a component of the neurophysiological mechanism by which drug level regulates drug-taking behavior during an ongoing self-administration session.

Key words: addiction; self-administration; drug; cocaine; psychomotor stimulant; nucleus accumbens; neuron; electrophysiology; reinforcement; reward; incentive motivation; locomotion; stereotypy
Lesion and microinjection studies in the rat have shown that neurons of the nucleus accumbens (NAcc) are necessary for cocaine self-administration (Phillips et al., 1983; Zito et al., 1985; Robledo et al., 1992; McGregor and Roberts, 1993). Consistent with this observation, single NAcc neurons show phasic changes in firing time locked to intravenous cocaine self-administration (Carelli et al., 1993; Carelli and Deadwyler, 1994, 1996a,b; Chang et al., 1994, 1996, 1998; Peoples et al., 1994, 1996, 1997, 1998; Bowman et al., 1996; Uzwiak et al., 1997). One of the most common changes in firing occurs during the interval that elapses between successive cocaine self-infusions. Firing rate decreases during the first $1 \mathrm{~min}$ after cocaine self-infusion, relative to the last $1 \mathrm{~min}$ before self-inf usion. The postinf usion change in firing is followed by a progressive reversal of that change, which begins within 2 min after the infusion and is not complete until the last 1 min before the next self-infusion (termed change + progressive reversal firing pattern) (Peoples and West, 1996).

We have hypothesized that this NAcc firing pattern contributes to cocaine self-administration. However, casual observation of behavior during the interinfusion interval suggests an alternative interpretation of the firing pattern. During the interinfusion interval, animals engage in a regular pattern of locomotion that

Received March 12, 1998; revised July 2, 1998; accepted July 7, 1998.

This work was supported by National Institute on Drug Abuse Grant DA 06886. Ms. Sejal Vyas and Ms. Binaifer Mohta contributed to video and data analysis. Ms. Linda King conducted the histological procedures, and Mr. Bruno Molino assisted in surgical procedures.

Correspondence should be addressed to Dr. L. L. Peoples, Department of Psychology, Rutgers University, New Brunswick, NJ 08903.

Copyright (C) 1998 Society for Neuroscience $0270-6474 / 98 / 187588-11 \$ 05.00 / 0$ parallels the change + progressive reversal firing pattern. Research of other investigators has shown that the NAcc contributes to locomotion (Lorens et al., 1970; Pijnenburg and van Rossum, 1973; Costall and Naylor, 1975; Jackson et al., 1975; Kelly et al., 1975; Kelly and Iversen, 1976; Iversen and Koob, 1977; Watchtel et al., 1979; Makanjuola et al., 1980; Jones et al., 1981; Mogenson and Nielsen, 1984; Evenden and Carli, 1985; Kafetzopoulos, 1986; Delfs et al., 1990; Weissenborn and Winn, 1992; Wu et al., 1993; Maldonado-Irizarry and Kelley, 1995; Brudzynski and Gibson, 1997). In addition, the tonic firing rate of some NAcc neurons is modulated by locomotion (Peoples and West, 1990; Callaway and Henriksen, 1992; Chang et al., 1994, 1998; Peoples et al., 1994; Kiyatkin and Rebec, 1996). These data suggest that the change + progressive reversal firing pattern potentially reflects locomotor-related discharges rather than, or in addition to, selfadministration-related firing.

The extent to which locomotor-related firing may contribute to the change + progressive reversal firing pattern was evaluated in the present study. Extracellular recordings of single NAcc neurons were conducted in rats intravenously self-administering cocaine. The sessions were videotaped to document the behaviors that occur during the interinfusion interval, as well as to analyze the activity of individual neurons with respect to those behaviors. The video and neural analyses were used to test the following predictions. If the "locomotor interpretation" of the change + progressive reversal firing pattern is correct, the time course of the change + progressive reversal firing pattern should be highly correlated with the time course of the changes in locomotion. In addition, neurons that show the change + progressive reversal firing pattern should also show phasic changes in firing time 
locked to specific locomotion events. Finally, the change + progressive reversal firing pattern should be disrupted by the exclusion of all periods of locomotion from the calculation of firing rates during the minutes before and after cocaine self-infusion.

Parts of this paper have been published previously in abstract form (Peoples et al., 1997).

\section{MATERIALS AND METHODS}

The procedures used for surgery, postoperative maintenance of animals, self-administration, extracellular recording, and histology were described in a previous report (Peoples and West, 1996). Thus, only a brief description of each is provided here.

Subjects and neuron sample. Subjects of the present study were a subset of animals (8 of 14) included in a previous study (Peoples and West, 1996). No neurons were included other than those of the previous study. Inclusion of each subject in the present study was dictated by two electrophysiological criteria. First, at least one of the neural recordings made for that subject had to exhibit a minimum interspike interval consistent with the refractory period of a discriminated single neuron. Second, at least one of the recordings that met the first criterion had to show additionally the phasic firing pattern of primary interest, i.e., the change + progressive reversal pattern. One subject had to be excluded because of a damaged videotape that precluded most of the analyses conducted in the present study.

Surgery. Long-Evans rats (300-350 gm; Charles River, Wilmington, MA) were anesthetized with sodium pentobarbital. A catheter was implanted in the jugular vein, and an array of 12-16 Teflon-coated stainless steel microwires was implanted in the NAcc (microwire arrays purchased from Dr. David Shapiro).

\section{Experimental procedures}

Cocaine self-administration session. Before the start of each selfadministration session, a nonretractable Plexiglas response lever was mounted on a side wall (henceforth referred to as the lever wall) of the chamber. Onset of the session was signaled by illumination of a stimulus light above the lever. Each lever press was immediately followed by a 0.2 $\mathrm{ml}$ intravenous infusion of cocaine solution $(0.24 \mathrm{mg} / 0.2 \mathrm{ml}$ infusion), a $7.5 \mathrm{sec}$ tone that corresponded with the operation of a syringe pump, and a $40 \mathrm{sec}$ time-out during which the stimulus light was turned off and lever presses had no programmed consequence.

Video recording. During each recording session, behavior was videotaped using a Sony Super VHS videocassette recorder. Each video frame (30 frames/sec) was sequentially time-stamped by a computer coupled with a video frame counter (Thalner Electronics VC-436). Frames were time stamped according to the same computer clock that time stamped each neural discharge. The camera viewed the animal through one of the Plexiglas chamber walls that was perpendicular to the lever wall. The entire chamber was visible; thus the rat was always visible. As the rat locomoted to the lever and then faced the lever to press it, the right flank of the rat was the typical view of the camera. As the rat locomoted away from the lever to the opposite side of the chamber, the left flank of the rat was in view of the camera. The side view of the rat facilitated detection of both forepaw and hindpaw movements as well as head movements.

Electrophysiological procedures. During each experiment, electrophysiological recording began $1 \mathrm{hr}$ before the start of the self-administration session and continued for $1 \mathrm{hr}$ after the session. Using software and hardware of DataWave Technologies (Longmont, CO), electrical signals were stored for off-line analysis. Only one recording session per microwire contributed to the final data set. After a population of neural waveforms was isolated by the post hoc discrimination procedures (DataWave Common Processing Module, DataWave Inc.), that population was subjected to an interspike interval analysis to confirm that it corresponded to a discriminated single neuron (Moore et al., 1966; Perkel et al., 1967; Kosobud et al., 1994). When more than a single population of neural waveforms appeared to have been recorded from a given wire, cross-correlation analysis was used to confirm that the populations corresponded to distinct neurons.

Histological procedures. All wire tips from which neurons were recorded were verified to have been located in the NAcc. Histological procedures have already been discribed (Peoples and West, 1996). Given the number of neurons that were included in the present analyses, we did not compare the firing patterns of neurons located in different areas of the NAcc.

\section{Analysis of behavior during the interinfusion interval}

The video system allowed us to document, off-line, the timing of behaviors completed in any area of the chamber with a temporal resolution of $33 \mathrm{msec}$. After the recording session, in off-line frame-by-frame analysis, time stamps associated with the onsets or offsets of particular behaviors were read from the video frames displayed on a video monitor. Frames in which the same type of behavioral event occurred were compiled and input as nodes into the computer (Chapin et al., 1980; West et al., 1997) for subsequent histogram analysis of neural firing in relation to specific behaviors. The use of video procedures in conjunction with strict operational definitions of behavior provided a more reliable characterization of the occurrence of specific behaviors than would have been possible using automated procedures. This is because the latter can potentially fail to discriminate between topographically distinct motor behaviors (Kehne et al., 1981; Kelly and Roberts, 1983; O’Dell et al., 1996). The video analysis of behavior was limited to those lever-press trials included in the analysis of neural firing (see below).

Operational definitions of behavior. Focused stereotypy was defined as a period in which the rat made repetitive head movements and/or repetitive forepaw movements while maintaining hindpaws stationary. The absence of hindpaw movements was associated with the rat remaining fixed (and behaviorally focused) in one area of the chamber. Locomotion was defined by a sequence of forepaw and hindpaw steps and thus involved traversal of the animal across the floor of the chamber. The presence versus absence of traversal maximally differentiated locomotion events from stereotypy events (i.e., differentiated major large movements from small repetitive movements, which is important for distinguishing between behaviors that are potentially mediated by the NAcc vs the lateral striatum) (see Kelly and Roberts, 1983; Wise and Bozarth, 1987). Mixed behavior consisted of some locomotive behavior, involving at least one hindpaw movement that occurred in conjunction with stereotypic head movement directed toward the floor of the chamber.

Onset and offset latencies of particular behaviors. Onset of locomotion equaled the time at which the paw that made the first step was lifted from the floor and offset of locomotion equaled the time at which the paw that made the last step contacted the floor. Nearly all focused stereotypy events were bracketed by either locomotion or mixed behavior. Therefore, the onset time of a stereotypy event was defined with respect to the last step of the locomotion or mixed event that preceded stereotypy. Similarly, the offset time of a stereotypy event was defined with respect to the first step of the locomotion or mixed behavior event that followed the stereotypy event.

Direction of locomotion. Each locomotion event was classified as either (1) toward the lever wall or (2) toward nonlever walls. Locomotion toward the lever wall was defined as forward locomotion that moved the animal in the direction of the lever wall and terminated with at least the head and shoulders of the rat inside the half-portion of the chamber that contained the lever. Forward or side-to-side locomotion that moved the animal from one portion of the lever wall to the other, with at least the head and shoulders of the rat in the quarter portion of the chamber containing the lever, was also classified as locomotion toward the lever wall. The remaining locomotion was defined as locomotion toward nonlever walls.

\section{Analysis of the change + progressive reversal firing pattern}

Histograms displaying firing of single neurons. The initial 5-10 irregularly spaced self-infusions of the loading phase were excluded from analysis. All other reinforced lever presses bracketed by interinfusion intervals of a minimum length (i.e., 1 min less than the modal interinfusion interval) were included in the histogram. Offset of the reinforced lever press $(0.1$ msec resolution) was the histogram node.

Quantitative and statistical analysis of the change + progressive reversal firing pattern. The procedures used to statistically analyze phasic changes in firing rate during the minutes before and after the press were described previously (Peoples and West, 1996). The procedures used to analyze decreases in firing rate are briefly described below. Comparable procedures were used to analyze increases in firing rate.

Significance was evaluated by using a one-tailed Wilcoxon matched pairs test ( $\alpha=0.05$, unidirectional; Siegel and Castellan, 1988). To conduct the test, firing rate before and after the reinforced lever press was calculated using a sliding window procedure (Schultz et al., 1992); the measure of firing rate, number of discharges, was determined as a function of $0.5 \mathrm{~min}$ time windows using a step time equal to $0.1 \mathrm{~min}$. For each lever-press trial that was included in a Wilcoxon matched pairs test, 
the discharges in two time windows, or in two 0.1 min steps, were input as a matched pair into the test.

Postpress change in firing rate. A postpress decrease in firing rate was defined as a significant decrease in firing rate that occurred during the first $2 \mathrm{~min}$ after the reinforced lever press, relative to firing during the last $2 \mathrm{~min}$ before the reinforced lever press. In analyzing a postpress decrease, the number of discharges in the $0.5 \mathrm{~min}$ time window with the minimum discharges after the press was compared with the number of discharges in the $0.5 \mathrm{~min}$ window with the maximum discharges before the press. The latency to culmination of the postpress decrease was defined as the 0.1 min step in which firing decreased to its minimum during the 2 min postpress.

Progressive reversal of postpress change. After culmination of the postpress decrease, firing rate began to revert toward prepress rates. The latency to onset of the reversal was defined as the first $0.1 \mathrm{~min}$ step in which firing reverted significantly from the culminant (minimum) firing rate of the postpress decrease. The latency to culmination of the reversal was defined as the 0.1 min step with the maximum discharges during the 2 min prepress.

\section{Relationship between the time course of the change +} progressive reversal firing pattern and the timing of locomotion

After the lever press, subjects typically locomoted away from the lever wall and then engaged in stereotypy. After some time elapsed the animal reinitiated locomotion. The length of time that elapsed before locomotion was reinitiated appeared to vary positively with the duration of the progressive reversal phase of the change + progressive reversal firing pattern. To test this possibility, a Pearson product-moment correlation was calculated between this latency to reinitiate locomotion and the duration of the progressive reversal. The reinitiation of locomotion was defined as the first postinf usion locomotion event that met the following two criteria: (1) occurred after the $40 \mathrm{sec}$ time-out period, and (2) did not consist of the initial locomotion away from the response lever after the cocaine-reinforced lever press. This definition was based on the following. Preliminary characterization of locomotion patterns indicated that locomotion typically decreased to minimum within the first $40 \mathrm{sec}$ and/or after the initial locomotion away from the lever wall after self-infusion. Locomotion subsequently increased in frequency. The latency from the lever press to this increase in locomotion was the dependent variable of interest.

Duration of the postpress change and the progressive reversal. The change + progressive reversal firing pattern was divided into three phases: the postpress change, the reversal, and the postreversal period. The first two phases were defined above. The third, the postreversal period, was the number of minutes that elapsed between culmination of the reversal and the time of the next self-infusion. The combined duration of these three phases equaled the duration of the interinfusion interval. The duration of the postpress change equaled the onset latency for the reversal (defined above). The duration of the reversal was defined as: [interinfusion interval - (duration of postpress change + duration of postreversal period)]. Pearson product-moment correlations $(\alpha=0.05)$ were calculated between the various phases of the firing pattern and the duration of the interinfusion interval.

\section{Does NAcc firing concomitant with locomotion engender the change + progressive reversal firing pattern?}

Do neurons show a phasic change in firing rate time locked to locomotion? Histograms were constructed to display firing rate time locked to locomotion events that were preceded by focused stereotypy events. Each of the locomotion events used as a node to construct these histograms (1) was preceded by a focused stereotypy event, and (2) did not occur within $\pm 10 \mathrm{sec}$ of the reinforced lever press. The histogram node equaled the onset of locomotion. The average duration of focused stereotypy ranged from 2.3 to $11.6 \mathrm{sec}$. The average duration of locomotion ranged from 0.8 to $2.2 \mathrm{sec}$. Given the above criteria, the onset of locomotion necessarily corresponded to the end of the immediately preceding stereotypy event. A change in firing rate to the right of the histogram node, relative to the left, was indicative of a phasic change in firing associated with the transition from stereotypy to locomotion. Using the Wilcoxon matched pairs test, firing rate during the first $0.5 \mathrm{sec}$ of locomotion was compared with firing rate during a $0.5 \mathrm{sec}$ period of focused stereotypy (i.e., -1.0 to $-0.5 \mathrm{sec}$ before the onset of the locomotion) ( $\alpha=0.05$, unidirectional; Siegel and Castellan, 1988). Histograms were constructed to display firing during the following: (1) locomotion toward the lever wall, (2) locomotion toward nonlever walls, and (3) locomotion toward all walls.
Directionally opposed locomotion events that contributed to the histograms were temporally matched with respect to cocaine self-infusion. Differences in the phasic firing apparent in histograms of firing time locked to locomotion toward the lever wall versus locomotion toward nonlever walls could therefore not be attributed to differences in drug level. There were no EMG recordings. However, given that the locomotion events were comparably defined except for direction, differences in these histograms were also unlikely to reflect any movement parameter other than direction.

Effect on the progressive reversal firing pattern of excluding all periods of locomotion from the calculation of firing rate. Histograms that display firing during the minutes before and after the press were reconstructed using only periods in which the animal was engaged in focused stereotypy. The following procedures were used to construct the histograms. Each stereotypy event was subdivided into $1 \mathrm{sec}$ subunits. The last $1 \mathrm{sec}$ subunit of stereotypy was discarded. For each lever-press trial, the $1.0 \mathrm{sec}$ subunits were grouped according to time before and after the press in bins of $0.5 \mathrm{~min}$. The discharges that occurred during the $1.0 \mathrm{sec}$ subunits were summed within each $0.5 \mathrm{~min}$ bin for a given lever-press trial. Discharges per $0.5 \mathrm{~min}$ bin were then summed across all lever-press trials and plotted as a function of time before and after the press. Note that before summation of discharges across lever-press trials, the $0.5 \mathrm{~min}$ bins were equated for total number of $1.0 \mathrm{sec}$ subunits. This was accomplished by first determining the minimum number of subunits within any of the $0.5 \mathrm{~min}$ bins and then reducing the number of subunits in all other 0.5 min bins to equal that minimum. The deletions were distributed equally across trials and across portions of the $0.5 \mathrm{~min}$ bin. Thus comparison of firing rate during different $0.5 \mathrm{~min}$ bins before and after the press was not confounded by different sample sizes. This analysis is comparable to behavioral clamping techniques (c.f., Rank et al., 1983) used to discriminate between firing patterns that reflect a primary drug effect and firing patterns that instead reflect feedback from drug-induced behaviors (e.g., West et al., 1992, 1997; Haracz et al., 1993; Peoples et al., 1994).

\section{RESULTS}

\section{Neuron sample}

Recordings of 18 neurons in eight animals met all the criteria for inclusion in the present study. One subject contributed four neurons. Each of the remaining seven subjects contributed between one and three neurons. The recordings of the 18 change + progressive reversal neurons were made during nine recording sessions using 17 microwires. Nine of the neurons were located in the core; the remaining neurons were in the shell and shell-core border areas. Each neuron exhibited a stable waveform throughout the recording session and exhibited a minimum interspike interval of 3-5 msec (Fig. 1). For 15 of the 18 neurons, the change + progressive reversal pattern consisted of a decrease in firing after the press followed by a progressive increase (abbreviated as decrease + progressive increase) (Fig. 2, neuron $B$ ). For the remaining neurons, it consisted of an increase in firing after the press followed by a progressive decrease (abbreviated as increase + progressive decrease) (Fig. 2, neuron $F$ ). Ten additional neurons, which were not considered further in the present analyses, exhibited either a phasic change in firing during the minutes before and after the press that was other than the change + progressive reversal firing pattern (5 of 10) or failed to show any phasic change in firing during the minutes before and after the press (i.e., were nonresponsive).

The qualitative and quantitative characteristics of the change + progressive reversal firing patterns of the neurons in the present study were comparable to those of the larger group of neurons from which the present subset was drawn (Peoples and West, 1996). They were also comparable to those of a larger and separate sample of NAcc neurons (see Peoples et al., 1998). Animals' self-administration behavior was consistent with that typically observed in limited-access (fixed ratio 1) cocaine selfadministration studies. The present neural and behavioral data are thus likely to be representative. 


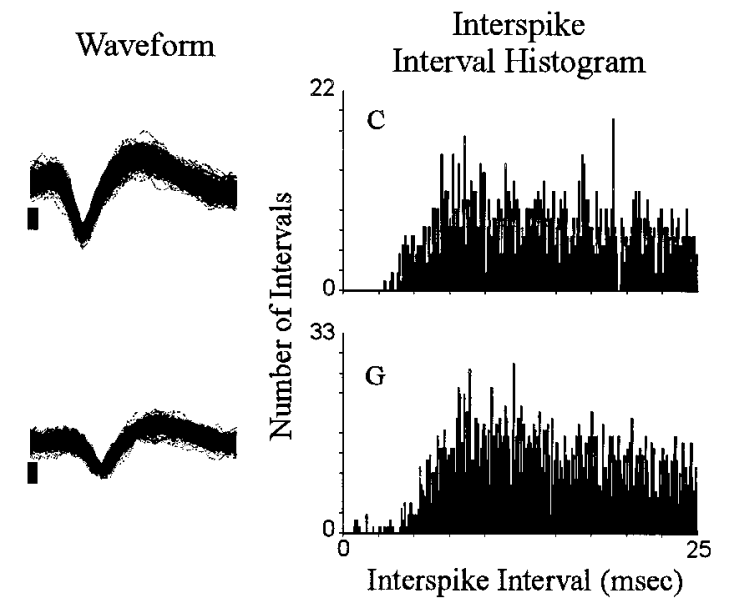

Figure 1. Interspike interval histograms. Each of the two rows shows an interspike interval histogram for a single neuron. Each histogram plots the total number $(0.1 \mathrm{msec}$ bin width) of interspike intervals (ordinate) exhibited by the neuron during the entire recording session that were of durations, $\geq 0.1 \mathrm{msec}$ and $\leq 25.0 \mathrm{msec}$ (abscissa). To the left of each histogram is a sample of the corresponding neural waveform. The sample consists of the first 500 consecutively recorded waveforms of the recording session. Positive voltage is up. The vertical calibration bar to the left of each waveform sample indicates $0.05 \mathrm{mV}$; each waveform trace spans 0.64 msec. In all figures, letters at top left of histograms correspond to identifying labels in other figures representing the same neurons.

\section{Self-administration behavior}

Animals had various amounts of self-administration experience (i.e., 2-6 weeks) and thus exhibited, to varying degrees, regular rates of self-infusion. The rates of infusion maintained a calculated drug level within correspondingly stable limits, assuming constant pharmacokinetics (Fig. 3).

\section{Behavior during the interinfusion interval \\ Locomotion}

Behavior consistent with the definition of locomotion accounted for a relatively low percentage of behavior exhibited during the interinfusion interval. Nevertheless, there were regular changes over the course of the interinfusion interval in the percent time that animals spent in locomotion as opposed to other behaviors. Within the first 1-1.5 min after the press, time spent in locomotion decreased to minimum (eight of eight animals) (Figs. 4, 5), which was typically (five of eight animals) maintained for several minutes and consisted of the complete absence of locomotion. Thereafter, animals reinitiated locomotion (average latency, $4.5 \pm 0.5 \mathrm{~min}$ after the press). Percent time spent in locomotion progressively increased as the interval elapsed such that locomotion was at maximum during the $\pm 0.5 \mathrm{~min}$ of the lever press. The patterns of locomotion toward the lever and nonwall walls were comparable (Fig. 6).

\section{Mixed behavior}

Most of the behavior that did not meet the strict definition of either stereotypy or locomotion consisted of mixed behavior. Changes in mixed behavior that occurred over the course of the interinfusion interval were comparable to the changes in locomotion (Fig. 5). The patterns of both locomotion and mixed behavior, which included locomotion, were similar in form to the change + progressive reversal firing pattern.

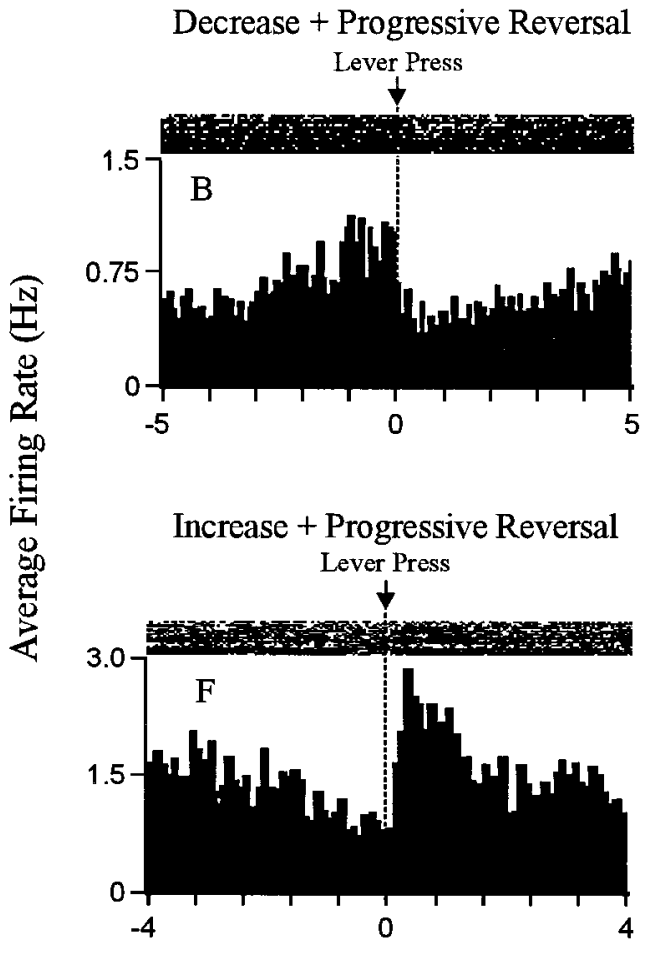

Time Pre- and Post Press (min)

Figure 2. Examples of the change + progressive reversal firing pattern. Each histogram displays the firing pattern of one neuron during the minutes before and after the press. The ordinate of each histogram displays average firing rate (i.e., average hertz calculated as a function of 0.1 min bins); Time 0 on the abscissa represents the occurrence of the reinforced lever press. Minutes before and after the press are shown to the left and right of time 0 , respectively. Above each histogram is a raster display that shows firing of the neuron on a trial-by-trial basis. Lever-press trials are shown chronologically from the bottom row to the top row. The figure shows examples of both types of change + progressive reversal firing patterns. A decrease + progressive increase pattern is shown at the top; an increase + progressive decrease pattern is shown at the bottom.

\section{Stereotypy}

Stereotypy was the predominant behavior during the interinfusion interval. Total percent time spent in stereotypy was $>70 \%$ for each animal. Time spent in stereotypy showed a regular pattern during the interinfusion interval that was opposite the pattern of locomotion (Figs. 4, 5).

Relationship between the time course of the change + progressive reversal firing pattern and the time course of locomotion

Firing rates of NAcc neurons and percent time spent in locomotion: Latency to minimum and maximum during the interinfusion interval

For the progressive reversal neurons that showed a postpress decrease in firing, the minimum firing rate (i.e., culminant of the postpress change) occurred, on average, $0.85 \pm 0.12 \mathrm{~min}$ after the press. The maximum firing rate (i.e., culminant of the progressive reversal) occurred, on average, $0.43 \pm 0.16 \mathrm{~min}$ before the press. These latencies to minimum and maximum firing rate corresponded to the times at which minimum and maximum locomotion occurred during the interinfusion interval. Neurons that showed a postpress increase in firing showed culminant latencies (i.e., latencies to maximum firing rate after the press and mini- 


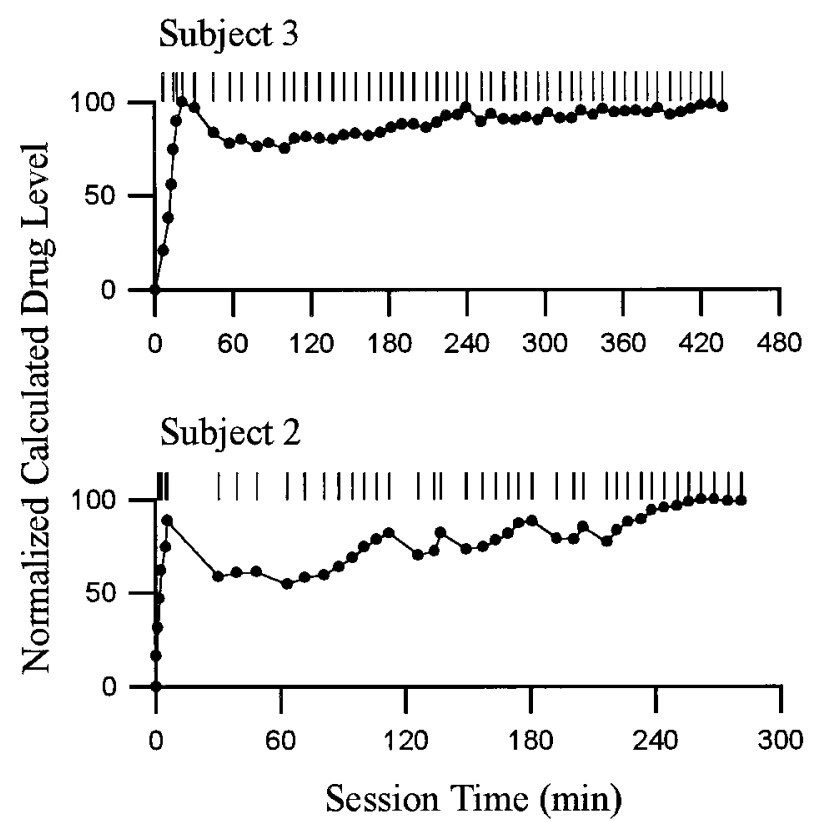

Figure 3. Patterns of lever presses and calculated drug level. Each of the two rows shows the self-administration behavior of a single animal during a single self-administration session. For each behavioral display, the following is shown. The abscissa shows time (minutes) during the selfadministration phase of the recording session; Time 0 corresponds to time of the first lever press. The pattern of reinforced lever presses is shown at the top. Each tick represents the occurrence of one cocaine reinforced lever press. Underneath the display of lever presses is a graph of the normalized calculated drug level present at the time of the self-infusion behavior (i.e., before the onset of the infusion) (c.f., Peoples et al., 1997). Calculated drug levels were normalized within each session relative to the maximum calculated drug level attained in the session. Although the calculated drug level (data not shown) may have differed from the actual drug level by some constant amount, the relative stability of the calculated drug level across the self-administration session demonstrates the degree to which the rate of self-inf usion was likely to have maintained body levels of drug within stable limits (c.f., Yokel and Pickens, 1974). The patterns of behavior shown are representative of the range of regularity in selfadministration behavior exhibited by subjects in the present study.

mum firing rate before the press) that were comparably synchronized to locomotion.

\section{Time course of the progressive reversal and reinitiation of} locomotion during the interinfusion interval

Average latency to onset of the progressive reversal equaled $1.4 \pm$ $0.2 \mathrm{~min}$ after the press. The latency to reinitiate locomotion averaged $4.5 \mathrm{~min}$ after the press. Thus, the progressive reversal was typically under way for several minutes before animals reinitiated locomotion. Despite the lag time between the onset of the progressive reversal and the onset of locomotion, both firing rate (of most neurons) and locomotion showed a progressive increase during the minutes before the press. Moreover, the duration of the progressive reversal was significantly positively correlated with both the latency to reinitiate locomotion toward the lever wall and the latency to reinitiate locomotion toward nonlever walls (Fig. 7). These correlations showed that the longer the period over which firing rate progressively reversed, perhaps recovered, from the postpress change in firing, the longer the animal waited after the preceding infusion to reinitiate locomotion.
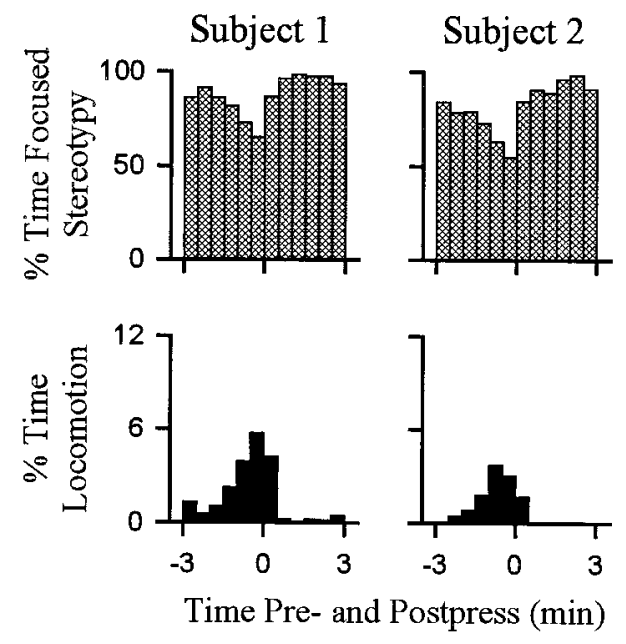

Figure 4. Percent time spent by individual subjects in locomotion and stereotypy. Each of the two columns shows the percent of time (ordinate) that a single animal spent in either stereotypy (top row) or locomotion (bottom row) during all the lever-press trials combined (i.e., all lever-press trials included in histogram analysis of firing). Time 0 on the abscissa represents occurrence of the reinforced lever press. Minutes before and after the press are shown to the left and right of time 0 , respectively. Subjects 1 and 2 correspond to neurons $D$ and $B$ shown in other figures.

\section{Did NAcc firing concomitant with locomotion engender the change + progressive reversal firing pattern?}

Phasic changes in firing rate time locked to locomotion

A total of $10(55 \%)$ of the 18 neurons showed a significant phasic change in firing rate time locked to locomotion. These 10 neurons were distributed among the two types of change + progressive reversal neurons as follows. Of the 15 decrease + progressive increase neurons, 7 showed a significant increase in firing rate time locked to locomotion relative to stereotypy (Fig. 8, neuron $D$ ). The increase in firing time locked to locomotion was consistent with the change in firing that would have been expected if firing associated with locomotion contributed to the change + progressive reversal firing pattern. The remaining 8 of the 15 decrease + progressive reversal neurons showed no change in firing time locked to locomotion. Of the three increase + progressive $d e$ crease neurons, one showed a small but significant decrease in firing rate time locked to locomotion compared with stereotypy (Fig. 8, neuron $E$ ). For that neuron, the phasic change in firing time locked to locomotion was consistent with that which could have potentially contributed to the change + progressive reversal firing pattern. The remaining two increase + progressive decrease neurons showed a significant increase in firing time locked to locomotion (Fig. 9, neuron $F$ ). The increase in firing time locked to locomotion exhibited by those neurons would have been expected to actually oppose the change + progressive reversal firing pattern. Taken together, these data showed that phasic changes in firing time locked to locomotion were unlikely to have engendered the change + progressive reversal firing pattern of $55 \%$ of the 18 neurons (i.e., $8 / 15$ decrease + progressive reversal neurons and $2 / 3$ increase + progressive reversal neurons). The same data left open the possibility that firing time locked to locomotion determined the change + progressive reversal firing pattern for the remaining $45 \%$ of the neurons (i.e., $7 / 15$ decrease + progressive reversal neurons and $1 / 3$ increase + progressive reversal neurons). 


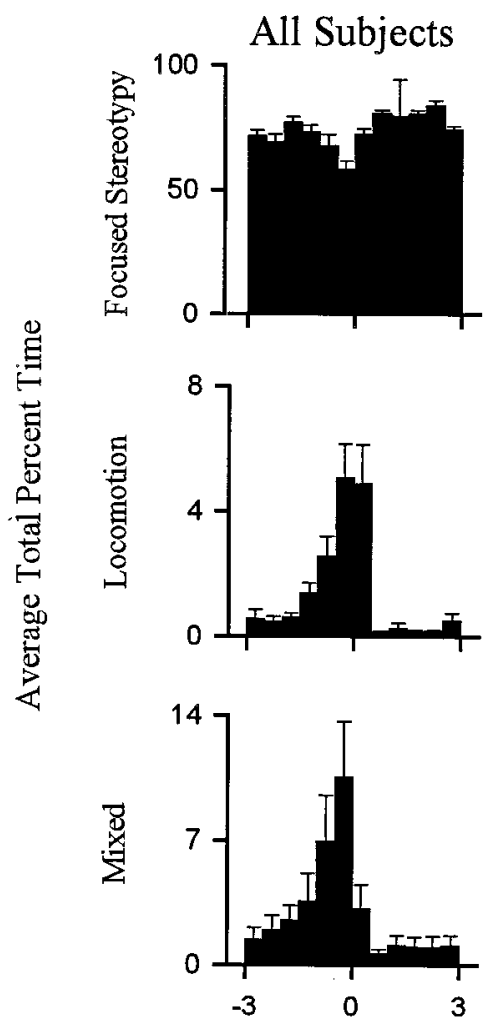

Time Pre- and Postpress ( $\mathrm{min})$

Figure 5. Average percent time spent in locomotion and stereotypy exhibited by all subjects. Each behavioral histogram shows the average percent of total time spent in a particular behavior by all animals combined.
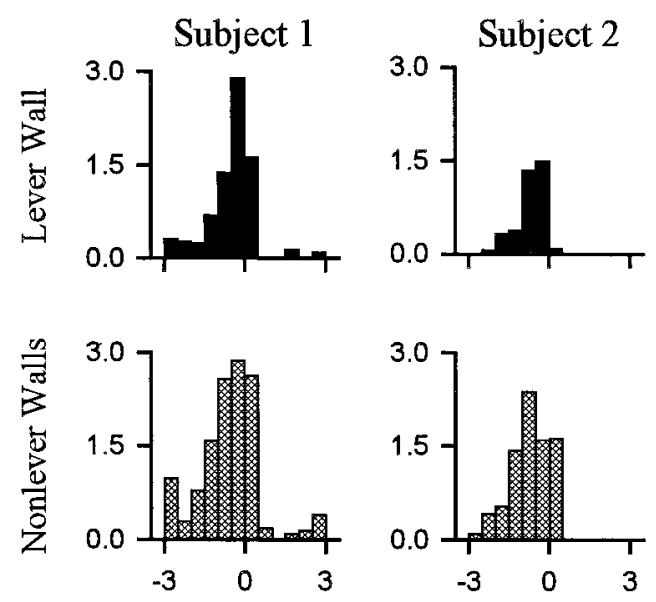

Time Pre- and Postpress (min)

Figure 6. Average percent time spent in locomotion toward the lever and nonlever walls. Each of the two columns displays the percent of total time that an individual animal spent engaged in either locomotion toward the lever wall (top row) or locomotion toward nonlever walls (bottom row). The two animals represented in this figure are the same animals represented in Figure 4.

Phasic changes in firing time locked to locomotion tended to be specific for locomotion of a given direction

Further analysis of the 10 neurons that fired phasically during locomotion showed that for $9(90 \%)$ of them firing was not

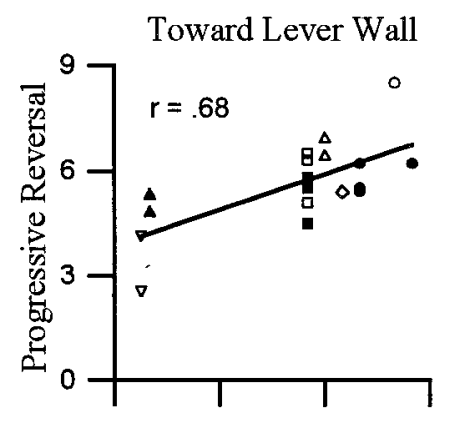

Toward Nonlever Walls
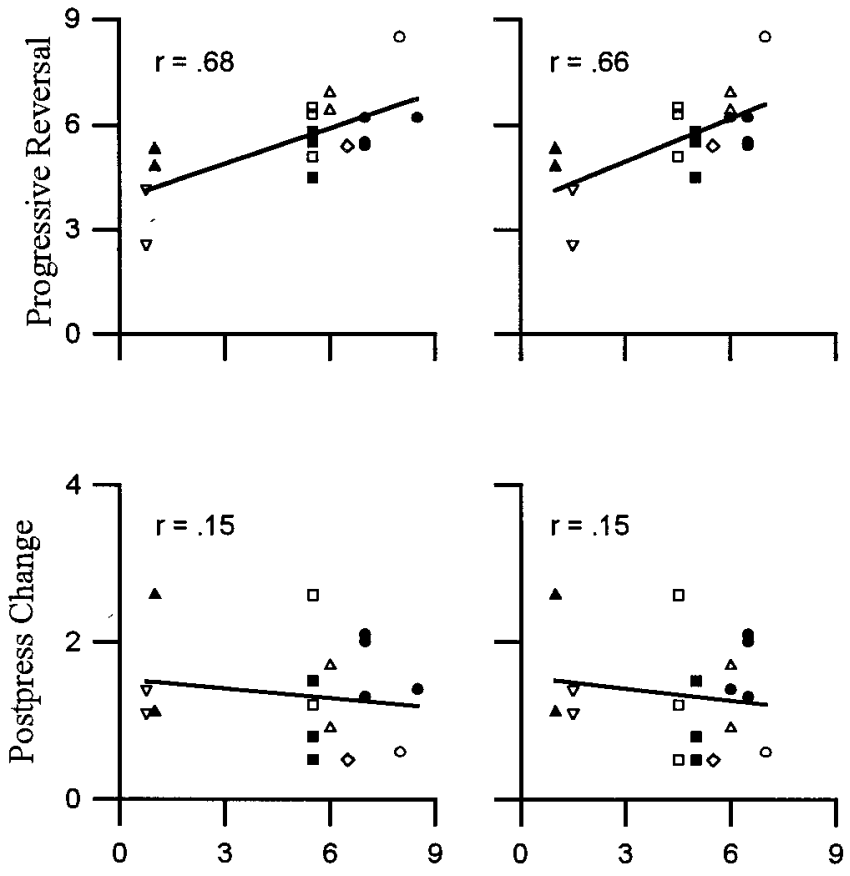

Latency to First Locomotion Postpress (min)

Figure 7. Duration of the progressive reversal phase of the change + progressive reversal firing pattern was correlated with the latency to reinitiate locomotion. Each of the four scatter plots corresponds to one Pearson product-moment correlation analysis. Each point in a scatter plot represents a single neuron. Points that correspond to the same subject are indicated by a unique geometric shape (total of 8 shapes). The ordinates display the duration (minutes) of either the progressive reversal (top row) or the postpress change (bottom row). The abscissas in all scatter plots show the modal postpress time (i.e., minutes after the press) at which locomotion was reinitiated during the interinf usion interval. Correlations were calculated separately for locomotion toward the lever wall (left scatter plot) and locomotion toward nonlever walls (right scatter plot). The Pearson product-moment correlations are shown in the top left corners of the scatter plots. The latency to reinitiate locomotion was significantly correlated with the duration of the progressive reversal regardless of locomotion direction $(p<0.5)$. Correlations with the duration of the postpress change were not significant $(p>0.5)$.

uniform among all locomotion events. Rather, the firing tended to vary depending on the direction of locomotion. For six neurons this "directional specificity" consisted of either (1) a change in firing time locked to locomotion toward the lever wall that was opposite in sign to the change in firing time locked to locomotion toward nonlever walls, or (2) a change in firing that occurred during locomotion of one direction, with no change in firing occurring during the locomotion of the other direction (Fig. 9, neurons $K, F)$. For three neurons, the directional specificity was quantitative rather than qualitative. Specifically, firing rate was elevated during all locomotion; however, the increase in firing was more robust and tightly time locked to locomotion toward the lever wall than to locomotion toward nonlever walls. The directional specificity of firing during locomotion indicated that even if firing time locked to locomotion contributed to the change + progressive reversal firing pattern of some neurons, the contribution was unlikely to have reflected an influence of general locomotor processing. 


\section{Locomotor Firing Consistent with Progressive Reversal}

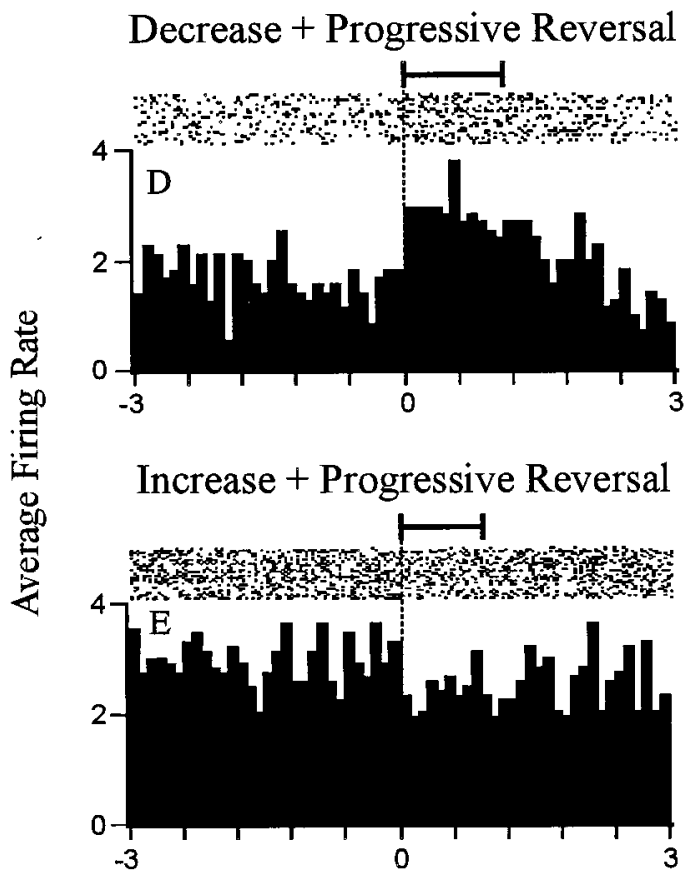

Pre- and Post-Onset of Locomotion (sec)

Figure 8. Neurons that showed locomotor-related firing consistent with the change + progressive reversal firing pattern. Each histogram shows a phasic change in firing time locked to the onset of locomotion. The top histogram shows the phasic change in firing time locked to locomotion that was exhibited by one decrease + progressive increase neuron (neuron $D$ ); the bottom histogram shows the same for one increase + progressive decrease neuron (neuron $E$ ). The following are shown for each neuron. Time 0 represents the onset of locomotion. Seconds before and after the onset of locomotion are shown to the left and right of time 0 , respectively. Firing during locomotion is thus shown on the right, and firing during focused stereotypy is shown on the left. At the top of the histogram is a raster display that shows firing on a trial-by-trial basis. The horizontal bar above the raster indicates the average duration of the locomotion events used to construct the histograms (exceeded $1.0 \mathrm{sec}$ ). The average duration of the focused stereotypy events that preceded the locomotion events exceeded the time base of the histograms. Letters at the top left correspond to identifying labels in other figures representing the same neurons.

\section{Effect of excluding all periods of locomotion from the} calculation of firing rate

For all 18 neurons, the progressive reversal firing pattern persisted when firing rates were calculated using only periods of focused stereotypy. This finding is demonstrated for four individual neurons in Figure 10 (see group mean histograms in Fig. 11). Each of the four neurons showed a phasic change in firing time locked to locomotion that was of a sign consistent with that which would have been expected if locomotor firing determined the change + progressive reversal firing pattern (e.g., Figs. 8, 10, neuron $D$ ). The results of this analysis did not completely exclude the possibility of a minor contribution of firing time locked to locomotion to the absolute firing rate of some neurons (Fig. 10, neuron $D$ ). However, it demonstrated that for all neurons in the present study, the change + progressive reversal firing pattern could not have been determined solely by the differential occurrence of locomotion during the interinfusion interval.

\section{DISCUSSION}

\section{Relationship between firing of NAcc neurons and the} occurrence of locomotion

A number of previous studies showed that NAcc neurons exhibit changes in overall firing rate during periods of locomotion (Peoples and West, 1990; Peoples et al., 1994; Callaway and Henriksen, 1992; Chang et al., 1994; Kiyatkin and Rebec, 1996). The present study extended these previous electrophysiological observations and showed that a substantial number of NAcc neurons exhibit a phasic change in firing time locked to locomotion. Moreover, the present data suggest that phasic firing tends to be specific for locomotion that is of a particular direction. The directional specificity indicates that locomotion and NAcc firing are not related in a one-to-one manner as if NAcc discharges cause the efferent signals mediating the execution of locomotor movements or process somatosensory feedback associated with its execution. These new data regarding phasic firing time locked to locomotion are consistent with the findings of numerous studies that have led researchers to propose that the NAcc does not directly mediate the execution of movements. Instead, the NAcc may have a motivational function that facilitates certain types of approach behaviors (Iversen and Koob, 1977; Mogenson et al., 1980; Robbins and Everitt, 1982; Kelley and Stinus, 1985; Fibiger and Phillips, 1986; Wise and Bozarth, 1987; Everitt et al., 1989; Mogenson and Yim, 1991; Phillips et al., 1991; Apicella et al., 1992; Blackburn et al., 1992; DiChiara et al., 1992; Salamone, 1992; Robinson and Berridge, 1993; Floresco et al., 1997).

Discharges time locked to locomotion: contribution to NAcc firing patterns that occur in relation to cocaine self-administration

\section{Present findings}

In the present study, during the minutes before and after selfinfusion, animals engaged in a predictable pattern of behavior in which stereotypy predominated and locomotion increased over the course of the interinf usion interval. These present data corroborated and quantified previous qualitative observations regarding the behavior of animals during cocaine selfadministration sessions (e.g., Pickens et al., 1978; Peoples and West, 1990; Woolverton and Johnson, 1992; Carelli et al., 1993; Chang et al., 1994). In the present study the pattern of locomotion was comparable in form to the change + progressive reversal firing pattern. These data suggested that the change + progressive reversal firing pattern might have been determined by firing time locked to locomotion. Further analysis showed that this was not so. First, the onset of the progressive increase in locomotion after the press lagged behind the onset of the progressive increase in firing. Second, $>50 \%$ of the neurons failed to show firing time locked to locomotion that could have potentially contributed to the progressive reversal pattern. Third, for all neurons, the change + progressive reversal firing pattern persisted when firing rates were calculated using only periods of stereotypy and thus when all locomotor firing was factored out. Given that the firing pattern persisted with both amount and type of behavior held constant across all time points ( $0.5 \mathrm{~min}$ resolution), this latter finding also largely ruled out the possibility that the change + progressive reversal firing pattern was determined by firing during any other specific behavior.

\section{Previous findings}

In addition to exhibiting changes in firing during the minutes before and after the press, such as the change + progressive 

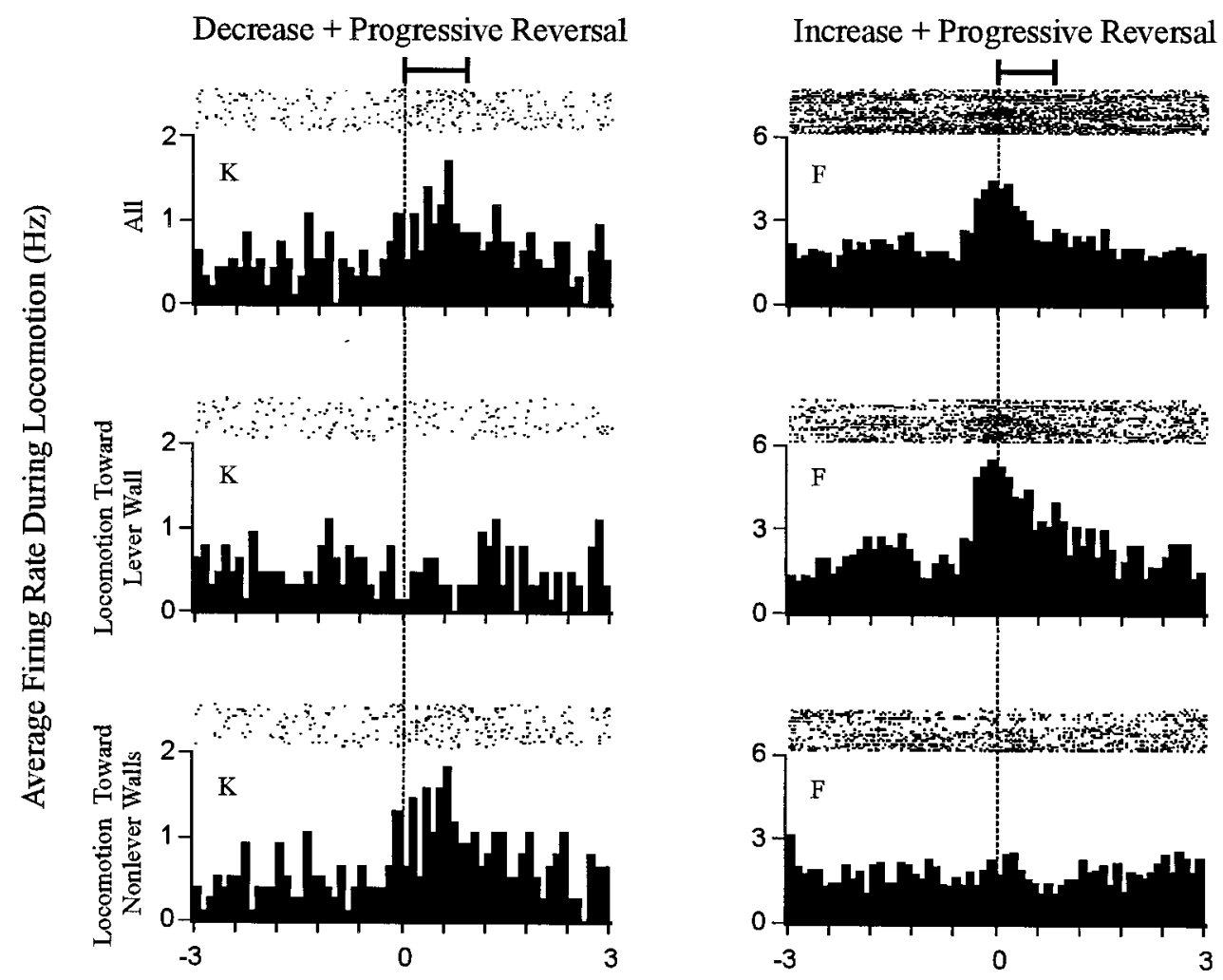

Figure 9. Phasic changes in firing rate time locked to locomotion were directionally specific for most neurons. Each histogram shows firing time locked to the onset of locomotion. Data are shown for two neurons, one decrease + progressive reversal neuron (left column) and one increase + progressive reversal neuron (right column). The neuron represented in the left column showed a change in firing time locked to locomotion that was specific for locomotion toward the nonlever walls. The neuron shown in the right column exhibited a change in firing time locked to locomotion that was specific for locomotion toward the lever wall. For each neuron, firing is shown during all locomotion (top row), locomotion toward the lever wall (middle row), and locomotion toward nonlever walls (bottom row). The horizontal bar at the top of each column indicates the average duration of the locomotion events (i.e., all locomotion toward lever and nonlever walls combined) used to construct the histograms. The average duration of the focused stereotypy events that preceded the locomotion

Pre- and Post Onset of Locomotion (sec) events exceeded the time base of the histograms.

Decrease + Progressive Reversal Neurons
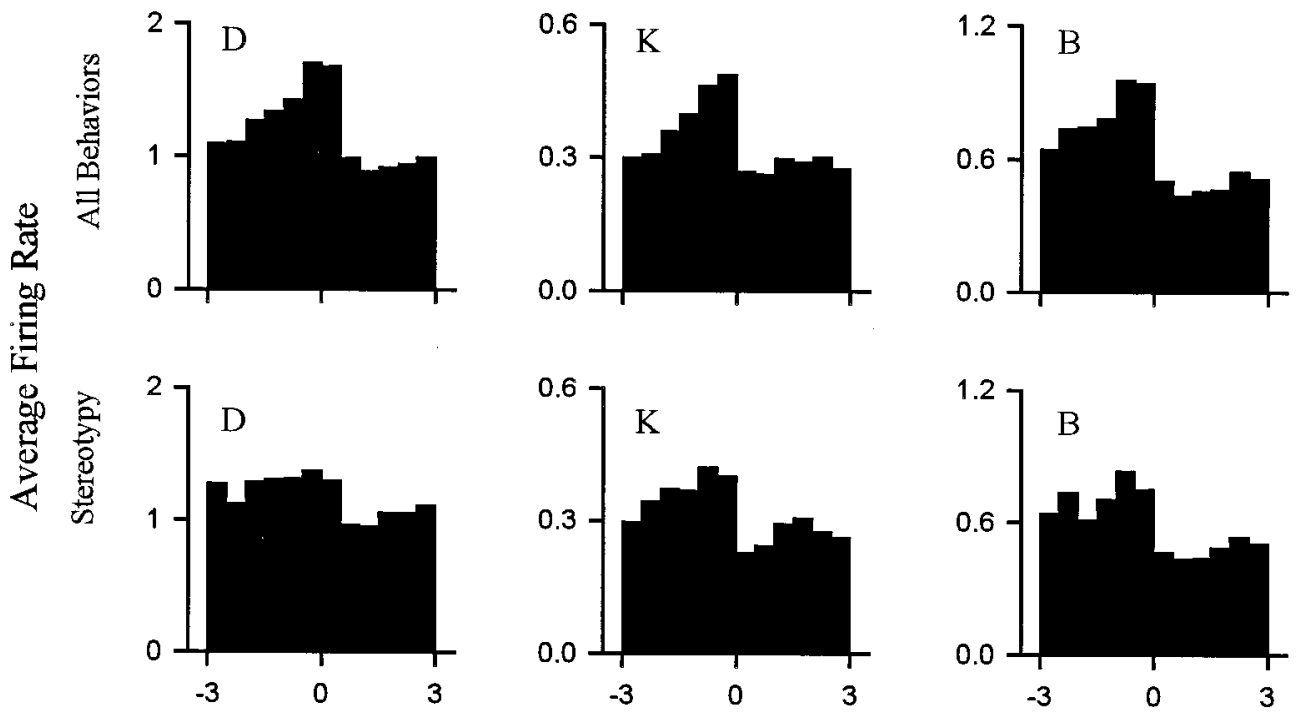

Increase + Progressive

Reversal Neuron
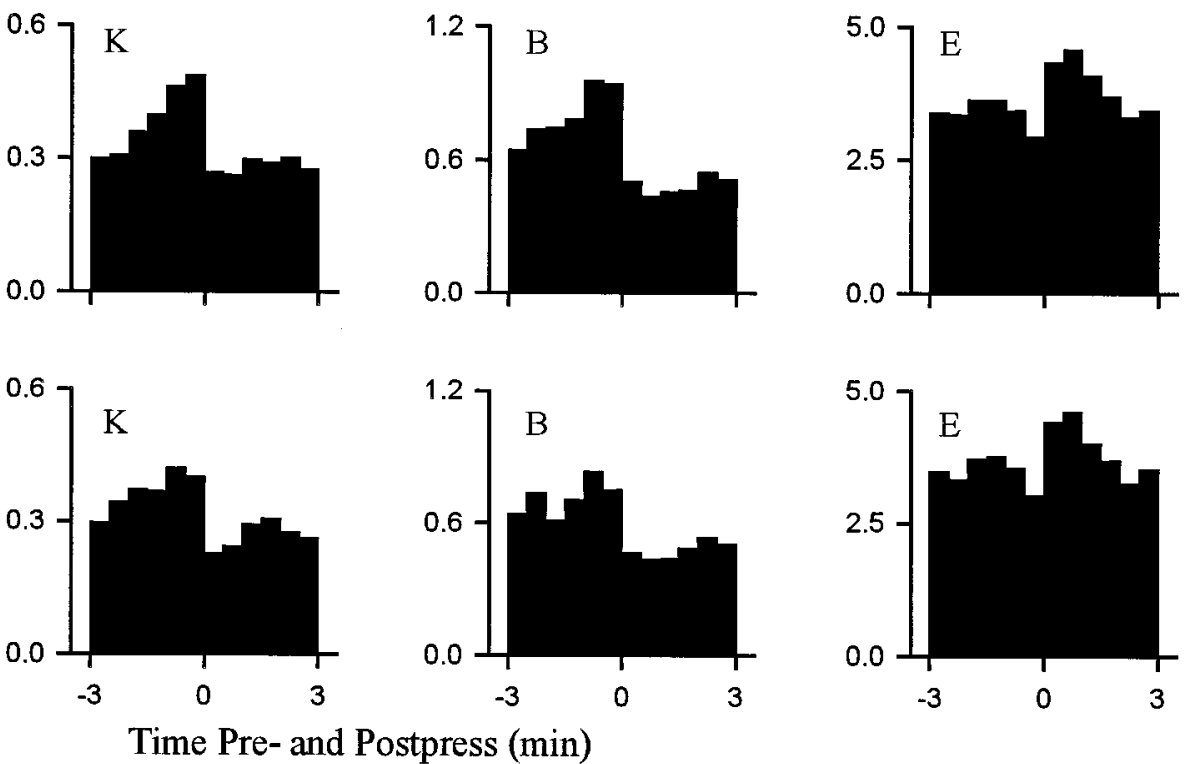

Time Pre- and Postpress (min)

Figure 10. The change + progressive reversal firing pattern persisted when all locomotion was excluded from calculations of firing rate. Each histogram shows the phasic change in firing time locked to the cocaine reinforced lever press. Data are shown for four neurons. Each column corresponds to a single neuron. The top row displays histograms constructed by calculating firing rate during all behaviors (i.e., shows the normal change + progressive reversal firing pattern). The bottom row shows histograms constructed by calculating firing rate during periods of only focused stereotypy. For each histogram the abscissa displays minutes before and after the press (Time 0 represents occurrence of the lever press.) The ordinate shows average firing rate (hertz). 
Decrease + Progressive Increase + Progressive Reversal Reversal

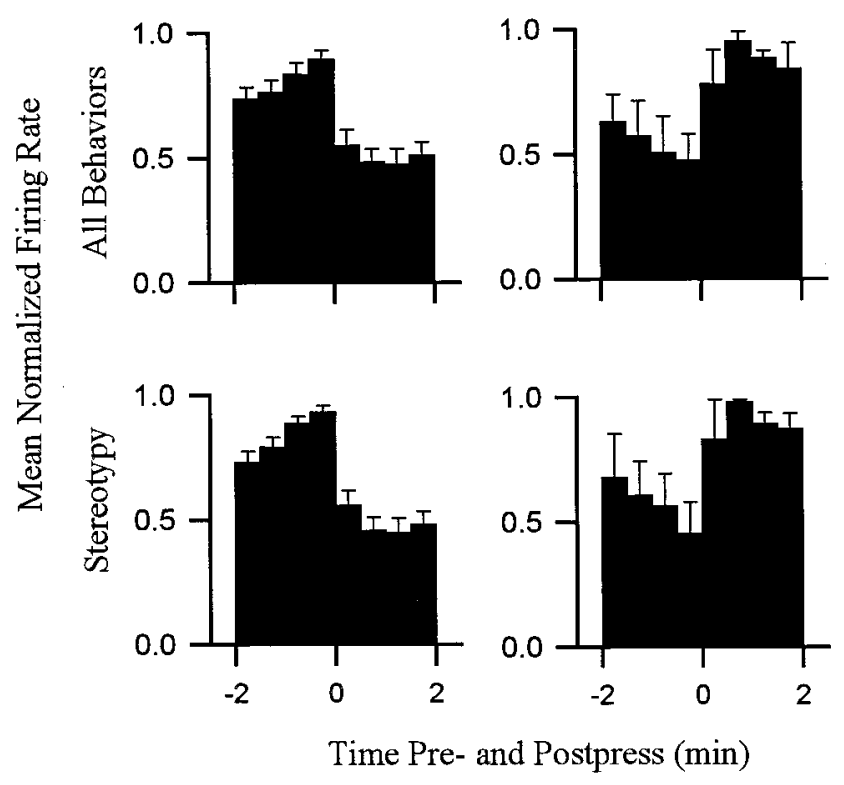

Figure 11. The change + progressive reversal firing pattern persisted when all locomotion was excluded from calculations of firing rate. Each histogram shows phasic firing time locked to the cocaine-reinforced lever press. Histograms shown in the left column correspond to all decrease + progressive reversal neurons combined $(n=15)$; Histograms in the right column correspond to all increase + progressive reversal neurons $(n=3)$. For each column, the top histogram displays firing during all behaviors, and the bottom histogram displays firing of the same neurons exclusively during stereotypy. Each histogram displays average normalized firing rate during the minutes before and after the press (ordinate). Firing rates within the histogram of each neuron were normalized by dividing hertz in each $0.5 \mathrm{~min}$ bin by the hertz in the $0.5 \mathrm{~min}$ bin showing the maximum firing rate in that histogram.

reversal firing pattern (Peoples and West, 1996), NAcc neurons show phasic changes in firing during the seconds before and after the press (Chang et al., 1990, 1994, 1996, 1998; Carelli et al., 1993; Carelli and Deadwyler, 1994, 1996a,b; Peoples et al., 1997; Uzwiak et al., 1997). Neurons additionally exhibit changes in firing during the entire self-administration session relative to presession nondrug baseline recording periods (referred to as tonic changes in firing) (Peoples and West, 1990; Peoples et al., 1994, 1998; West et al., 1992; Chang et al., 1998; for a related finding see Carelli and Deadwyler, 1994, 1996a). Like the change + progressive reversal firing pattern, the phasic changes in firing during the seconds before and after the press, as well as the tonic changes in firing, are associated with regular patterns of locomotion and thus potentially reflect discharges time locked to locomotion. However, on close examination, Chang et al. (1994) found that the phasic changes in firing during the seconds before and after the press are not completely synchronized with, and thus not entirely attributable to, the pattern of locomotion. Moreover, preliminary analysis of the tonic changes in firing showed that the differences in overall firing rate between the nondrug and self-administration period are not likely to be attributable solely to the differences in locomotion between those two conditions (Peoples and West, 1990; Peoples et al., 1994; West et al., 1992). In total, evidence that is currently available indicates that the changes in firing exhibited by NAcc neurons in temporal relation to cocaine self-administration are not determined solely by phasic changes in firing time locked to locomotion. Current data do not, however, show that firing during (certain) locomotion and firing time locked to self-administration are completely unrelated (see below).

\section{Firing time locked to locomotion and firing time locked to self-infusion may be temporally dissociable but nevertheless functionally related}

The present study showed that there are individual NAcc neurons that show both phasic firing time locked to self-administration and phasic firing time locked to locomotion of a specific direction. It is possible that the phasic firing patterns are functionally distinct. However, it is also possible that the firing patterns are functionally related. Specifically, both may facilitate movements regardless of form - whether it be walking, running, rearing, or lever pressing — as long as the movements are consistent with the same motivational end point. For example, the firing may facilitate any movement associated with approach toward a cocainerelated stimulus. Although speculative, this interpretation is consistent with the Hebbian concept of motor equivalence (Hebb, 1949). Moreover, it is consistent with many previous findings regarding the influence of the NAcc on behavior (see citations in first section of Discussion).

\section{Psychomotor stimulant theory}

Wise and Bozarth (1987) proposed that the psychomotoric locomotor-activating effects and reinforcing effects of drugs of abuse may be homologous and, moreover, may be commonly mediated, at least in part, by the NAcc. Other researchers have made similar proposals (e.g., Pulvirenti et al., 1991). The data supportive of this hypothesis are mixed (Wise and Bozarth, 1987; Burns et al., 1993; Robledo et al., 1993; Wise and Munn, 1993; Whitelaw et al., 1996; Gong et al., 1997). However, the finding of the present study that individual neurons show both phasic firing time locked to locomotion and phasic firing time locked to selfadministration is consistent with the psychomotor stimulant theory. In fact, the neurons that exhibit both types of firing are neurons that could theoretically underlie such a common contribution of the NAcc to locomotor activating and reinforcing effects of drugs of abuse.

\section{Possible contributions of the change + progressive reversal neurons to cocaine self-administration}

Phasic changes in firing time locked to cocaine self-infusion potentially contribute to drug-taking behavior. However, phasic firing in and of itself does not provide definitive evidence of a functional relationship between the activity of a recorded neuron and self-administration behavior. Numerous pharmacological, behavioral, and stimulus events are highly synchronized during the self-administration session. Careful step-by-step experimental discrimination of the potential contribution of these variables to the firing patterns is necessary to identify firing patterns that may contribute specifically to cocaine self-administration. The present study showed that the change + progressive reversal firing pattern is not attributable solely to phasic changes in firing time locked to locomotion (or to any other specific behavior) that occurs in parallel with the firing pattern. This finding eliminated one of the simplest alternative interpretations of the change + progressive reversal firing pattern and thereby added credence to the hypothesis that the firing pattern may be specifically related to drug self-administration.

The change + progressive reversal firing pattern is correlated with the timing of cocaine self-infusion (Peoples and West, 1996) 
and closely mirrors the changes in cocaine and dopamine that occur over the course of the interinfusion interval (e.g., Pettit and Justice, 1989; Wise et al., 1995). The latter are believed to regulate cocaine self-administration behavior during the selfadministration session. It is thus possible that the change + progressive reversal firing pattern is determined in large part by the oscillations in cocaine and dopamine and that the firing pattern in turn contributes to the transduction mechanisms by which mesoaccumbens drug and dopamine levels regulate drug taking. We have hypothesized that the rise and fall of drug level in the NAcc that occurs as a function of drug absorption and metabolism after each successive cocaine self-infusion lead to concomitant changes in accumbal throughput of afferent signals, perhaps including those that typically influence instrumental behavior. These changes in throughput may contribute to the bias of the animal to engage in drug-taking behavior as opposed to other behaviors over the course of the interinfusion interval (c.f., Peoples and West, 1996; Peoples et al., 1998).

\section{REFERENCES}

Apicella P, Scarnati E, Ljungberg T, Schultz W (1992) Neuronal activity in monkey striatum related to the expectation of predictable environmental events. J Neurphysiol 68:945-960.

Blackburn JR, Pfaus JG, Phillips AG (1992) Dopamine functions in appetitive and defensive behaviors. Prog Neurobiol 39:247-279.

Bowman EM, Aigner TG, Richmond BJ (1996) Neural signals in the monkey ventral striatum related to motivation for juice and cocaine rewards. J Neurophysiol 75:1061-1073.

Brudzynski SM, Gibson CJ (1997) Release of dopamine in the nucleus accumbens caused by stimulation of the subiculum in freely moving rats Brain Res Bull 42:303-308.

Burns LH, Robbins TW, Everitt BJ (1993) Differential effects of excitotoxic lesions of the basolateral amygdala, ventral subiculum, and medial prefrontal cortex on responding with conditioned reinforcement and locomotor activity potentiated by intra-accumbens infusions of d-amphetamine. Behav Brain Res 55:167-183.

Callaway CW, Henriksen SJ (1992) Neuronal firing in the nucleus accumbens is associated with the level of cortical arousal. Neuroscience 51:547-553.

Carelli RM, Deadwyler SA (1994) A comparison of nucleus accumbens neuronal firing patterns during cocaine self-administration and water reinforcement in rats. J Neurosci 14:7735-7746.

Carelli RM, Deadwyler SA (1996a) Cellular mechanisms underlying reinforcement-related processing in the nucleus accumbens: electrophysiological studies in behaving animals. Pharmacol Biochem Behav 57:495-504.

Carelli RM, Deadwyler SA (1996b) Dual factors controlling activity of nucleus accumbens cell-firing during cocaine self-administration. Synapse 24:308-311.

Carelli RM, King VC, Hampson RE, Deadwyler SA (1993) Firing patterns of nucleus accumbens neurons during cocaine self-administration in rats. Brain Res 626:14-22.

Chang J-Y, Sawyer S-F, Lee R-S, Maddux BN, Woodward DJ (1990) Activity of neurons in nucleus accumbens during cocaine selfadministration in freely moving rats. Soc Neurosci Abstr 16:252.

Chang J-Y, Sawyer SF, Lee R-S, Woodward DJ (1994) Electrophysiological and pharmacological evidence for the role of the nucleus accumbens in cocaine self-administration in freely moving rats. J Neurosci 14:1224-1244.

Chang J-Y, Paris JM, Sawyer SF, Kirillov AB, Woodward DJ (1996) Neuronal spike activity in rat nucleus accumbens during cocaine selfadministration under different fixed-ratio schedules. Neuroscience 74:483-497.

Chang J-Y, Janak PH, Woodward DJ (1998) Comparison of mesocorticolimbic neuronal responses during cocaine and heroin selfadministration in freely moving rats. J Neurosci 18:3098-3115.

Chapin JK, Loeb GE, Woodward DJ (1980) A simple technique for determination of footfall patterns of animals during treadmill locomotion. J Neurosci Methods 2:97-102.

Costall B, Naylor RJ (1975) The behavioral effects of dopamine applied intracerebrally to areas of the mesolimbic system. Eur J Pharmacol 32:87-92.

Delfs JM, Schreiber L, Kelly AE (1990) Microinjection of cocaine into the nucleus accumbens elicits locomotor activation in the rat. J Neurosci 10:303-310.

DiChiara G, Morelli M, Acquas E, Carboni E (1992) Functions of dopamine in the extrapyramidal and limbic systems. Drug Res 42:231-237.

Evenden JL, Carli M (1985) The effects of 6-hydroxydopamine lesions of the nucleus accumbens and caudate nucleus of rats on feeding in a novel environment. Behav Brain Res 15:63-70.

Everitt BJ, Cador M, Robbins TW (1989) Interactions between the amygdala and ventral striatum in stimulus-reward associations: studies using a second-order schedule of sexual reinforcement. Neuroscience 30:63-75.

Fibiger HC, Phillips AG (1986) Reward, motivation, cognition: psychobiology of mesotelencephalic dopamine systems. In: Handbook of physiology-the nervous system: intrinsic regulatory systems of the brain, Vol IV, Sect I (Bloom FE, ed), pp 647-675. Bethesda, MD: American Physiological Society.

Floresco SB, Seamans JK, Phillips AG (1997) Selective roles for hippocampal, prefrontal cortical, and ventral striatal circuits in radial-arm maze task with or without a delay. J Neurosci 17:1880-1890.

Gong W, Justice Jr JB, Neill D (1997) Dissociation of locomotor and conditioned place preference responses following manipulation of $\mathrm{GABA}_{\mathrm{A}}$ and AMPA receptors in ventral pallidum. Prog Neuropsychopharmacol Biol Psychiatry 21:839-852.

Haracz JL, Tschanz JT, Wang Z, White IM, Rebec GV (1993) Striatal single-unit responses to amphetamine and neuroleptics in freely moving rats. Neurosci Biobehav Rev 17:1-12.

Hebb DO (1949) The Organization of behavior: a neuropsychological theory. New York: Wiley.

Iversen SD, Koob GF (1977) Behavioral implications of dopaminergic neurons in the mesolimbic system. In: Advances in biochemical psychopharmacology, Vol 16 (Costa E, Gessa GL, eds), pp 209-214. New York: Raven.

Jackson DM, Andén N-E, Dahlström A (1975) A functional effect of dopamine in the nucleus accumbens and in some other dopamine-rich parts of the rat brain. Psychopharmacologia 45:139-149.

Jones DL, Mogenson GJ, Wu M (1981) Injections of dopaminergic, cholinergic, serotonergic, and gabaergic drugs into the nucleus accumbens. Effects on locomotor activity in the rat. Neuropharmacology 20:29-37.

Kafetzopoulos E (1986) Effects of amphetamine and apomorphine on locomotor activity after kainic acid lesion of the nucleus accumbens septi in the rat. Psychopharmacology 88:271-274.

Kehne JH, Sant WW, Sorenson CA (1981) The effects of radio-frequency lesions of the nucleus accumbens on d-amphetamine-induced locomotor rearing behavior in rats. Psychopharmacology 75:363-367.

Kelley AE, Stinus L (1985) Disappearance of hoarding behavior after 6-hydroxydopamine lesions of the mesolimbic dopamine neurons and its reinstatement with 1-dopa. Behav Neurosci 99:531-545.

Kelly PH, Iversen SD (1976) Selective 6-OHDA induced destruction of mesolimbic dopamine neurons: abolition of psychostimulant-induced locomotor activity in rats. Eur J Pharmacol 40:45-56.

Kelley PH, Roberts DC (1983) Effects of amphetamine and apomorphine on locomotor activity after 6-OHDA and electrolytic lesions of the nucleus accumbens septi. Pharmacol Biochem Behav 19:137-143.

Kelly PH, Seviour PW, Iversen SD (1975) Amphetamine and apomorphine responses in the rat following 6-OHDA lesions of the nucleus accumbens septi and corpus striatum. Brain Res 94:507-522.

Kiyatkin EA, Rebec GV (1996) Dopaminergic modulation of glutamate-induced excitations of neurons in the neostriatum and nucleus accumbens of awake, unrestrained rats. J Neurophysiol 75:142-153.

Kosobud AEK, Harris GC, Chapin JK (1994) Behavioral associations of neuronal activity in the ventral tegmental area of the rat. J Neurosci 14:7117-7129.

Lorens SA, Sorensen JP, Harvey JA (1970) Lesions in the nuclei accumbens septi of the rat: behavioral and neurochemical effects. J Comp Physiol Psychol 73:284-290.

Makanjuola ROA, Dow RC, Ashcroft GW (1980) Behavioral responses to stereotactically controlled injections of monoamine neurotransmitters into the accumbens and caudate-putamen nuclei. Psychopharmacology 71:227-235.

Maldonado-Irizarry CS, Kelley AE (1995) Excitotoxic lesions of the core and shell subregions of the nucleus accumbens differentially disrupt body weight regulation and motor activity in rat. Brain Res Bull 38:551-559. 
McGregor A, Roberts DCS (1993) Dopaminergic antagonism within the nucleus accumbens or the amygdala produces differential effects on intravenous cocaine self-administration under fixed and progressive ratio schedules of reinforcement. Brain Res 14:69-97.

Mogenson GJ, Nielsen M (1984) A study of the contribution of hippocampal accumbens-subpallidal projections to locomotor activity. Behav Neural Biol 42:38-51.

Mogenson GJ, Yim CC (1991) Neuromodulatory functions of the mesolimbic dopamine system: electrophysiological and behavioral studies. In: The mesolimbic dopamine system: from motivation to action. (Willner P, Scheel-Kruger J, eds), pp 105-131. New York: Wiley.

Mogenson GJ, Jones DL, Yim CY (1980) From motivation to action: functional interface between the limbic system and the motor system. Prog Neurobiol 14:69-97.

Moore GP, Perkel D, Segundo JP (1966) Statistical analysis and functional interpretation of neuronal spike data. Annu Rev Physiol 28:493-522.

O'Dell LE, Khroyan TV, Neisewander JL (1996) Dose-dependent characterization of the rewarding and stimulant properties of cocaine following intraperitoneal and intravenous administration in rats. Psychopharmacology 123:144-153.

Peoples LL, West MO (1990) Effects of intravenous cocaine on single unit activity in the nucleus accumbens of freely moving rats. Soc Neurosci Abstr 16:252.

Peoples LL, West MO (1996) Phasic firing of single neurons in the rat nucleus accumbens correlated with the timing of intravenous cocaine self-administration. J Neurosci 16:3459-3473.

Peoples LL, Bibi R, West MO (1994) Effects of intravenous selfadministered cocaine on single cell activity in the nucleus accumbens of the rat. In: Problems of drug dependence, 1993: proceedings of the 55th annual scientific meeting. The College on Problems of Drug Dependence, Inc. Vol II, (Harris L, ed), pp 326. Washington, D.C.: Superintendent of Documents, United States Government Printing Office. National Institute on Drug Abuse Research Monograph 141.

Peoples LL, Gee F, West MO (1997) Activity of neurons in the nucleus accumbens correlated with cocaine self-inf usion: relationship to behavior during the interinf usion interval. In: Problems of drug dependence, 1996: proceedings of the 58th annual scientific meeting. The College on Problems of Drug Dependence, Inc. (Louis S Harris, ed), pp 228. Washington, D.C.: Superintendent of Documents, United States Government Printing Office. National Institute on Drug Abuse Research Monograph 174.

Peoples LL, Uzwiak AJ, Gee F, West MO (1997) Operant behavior during sessions of intravenous cocaine infusion is necessary and sufficient for phasic firing of single nucleus accumbens neurons. Brain Res 757:280-284.

Peoples LL, Uzwiak AJ, Guyette FX, West MO (1998) Tonic inhibition of single nucleus accumbens neurons in the rat: a predominant but not exclusive firing pattern induced by cocaine self-administration. Neuroscience 86:13-22.

Perkel DH, Gerstein GL, Moore GP (1967) Neuronal spike trains and stochastic point processes. I. The single spike train. Biophys J 7:391-418.

Pettit HO, Justice Jr JB (1989) DA in the NAcc during cocaine selfadministration as studied by in vivo microdialysis. Pharmacol Biochem Behav 34:899-904.

Phillips AG, Broekkamp CLE, Fibiger HC (1983) Strategies for studying the neurochemical substrates of drug reinforcement in rodents. Prog Neuropsychopharmacol Biol Psychiatry 7:585-590.

Phillips AG, Pfaus JG, Blaha CD (1991) Dopamine and motivated behavior: insights provided by in vivo analyses. In: The mesolimbic dopamine system: from motivation to action (Willner P, Scheel-K J, eds), pp 199-224. New York: Wiley.

Pickens R, Meisch A, Thompson T (1978) Drug self-administration: an analysis of the reinforcing effects of drugs. In: Handbook of psychopharmacology, Vol 12 (Iversen LL, Iversen SD, Snyder SH, eds), pp 1-37. New York: Plenum.

Pijnenburg AJJ, van Rossum JM (1973) Stimulation of locomotor activity following injection of dopamine into the nucleus accumbens. J Pharm Pharmacol 25:1003-1005.

Pulvirenti L, Swerdlow NR, Hubner CB, Koob GF (1991) The role of limbic-accumbens pallidal circuitry in the activating and reinforcing properties of psychostimulant drugs. In: The mesolimbic dopamine system: from motivation to action (Willner P, Scheel-Kruger, eds), pp 131-140. New York: Wiley.

Rank Jr JB, Kubie JL, Fox SE, Wolfson S, Muller RU (1983) Single neuron recording in behaving mammal: bridging the gap between neuronal events and senory-behavioral variables. In: Behavioral approaches to brain research (Robinson TE, ed), pp 5-62. New York: Oxford UP.

Robbins TW, Everitt BJ (1982) Functional studies of the central catecholamines. In: International review of neurobiology, Vol 23 (Smythies JR, Bradley RJ, eds), pp 303-365. New York: Academic.

Robinson TE, Berridge KC (1993) The neural basis of drug craving: an incentive-sensitization theory of addiction. Brain Res Rev 18:247-291.

Robledo P, Maldonado-Lopez R, Koob GF (1992) Role of dopamine receptors in the nucleus accumbens in the rewarding properties of cocaine. In: The neurobiology of drug and alcohol addiction. Annals of the New York Academy of Sciences, Vol. 654 (Kalivas PW, Samson HH, eds), pp 509-512. New York: Academy Science.

Robledo P, Maldonado R, Koob GF (1993) Neurotensin injected into the nucleus accumbens blocks the psychostimulant effects of cocaine but does not attenuate cocaine self-administration in the rat. Brain Res 622:105-112.

Salamone JD (1992) Complex motor and sensorimotor functions of striatal and accumbens dopamine: involvement in instrumental behavior processes. Psychopharmacology 107:160-174.

Schultz W, Apicella P, Scarnati I, Ljungberg, T (1992) Neuronal activity on monkey ventral striatum related to the expectation of reward. J Neurosci 12:4595-4610.

Siegel S, Castellan Jr S (1988) Nonparametric statistics for the behavioral sciences. New York: McGraw-Hill.

Uzwiak AJ, Guyette FX, West MO, Peoples LL (1997) Neurons in accumbens subterritories of the rat: phasic firing time-locked within seconds of intravenous cocaine self-infusion. Brain Res 767:363-369.

Watchtel H, Ahlenius S, Andén N-E (1979) Effects of locally applied dopamine in the nucleus accumbens on the motor activity of normal rats and following $\alpha$-methyltyrosine or reserpine. Psychopharmacology 63:203-206.

Weissenborn R, Winn P (1992) Regulatory behavior, exploration, and locomotion following NMDA or 6-OHDA lesions in the rat nucleus accumbens. Behav Brain Res 51:127-137.

West MO, Peoples LL, Wolske M, Dworkin SI (1992) Psychomotor stimulant effects on single neurons in awake, behaving rats. In: Neurobiological approaches to brain-behavior. (Frascell J, Brown RM, eds), pp 57-72. Washington, D.C.: Superintendent of Documents, United States Government Printing Office. Interaction National Institute on Drug Abuse Research Monograph Series 124.

West MO, Peoples LL, Michael A, Chapin JK, Woodward DJ (1997) Low-dose amphetamine elevates movement-related firing of rat striatal neurons. Brain Res 745:331-335.

Whitelaw RB, Markou A, Robbins TW, Everitt BJ (1996) Excitotoxic lesions of the basolateral amygdala impair the acquisition of cocaineseeking behaviour under a second-order schedule of reinforcement. Psychopharmacology 127:213-224.

Wise RA, Bozarth MA (1987) A psychomotor stimulant theory of addiction. Psychol Rev 94:469-492.

Wise RA, Munn E (1993) Effects of repeated amphetamine injections on lateral hypothalamic brain stimulation reward and subsequent locomotion. Behav Brain Res 55:195-201.

Wise RA, Newton P, Leeb K, Burnette B, Pocock D, Justice Jr JB (1995) Fluctuations in nucleus accumbens dopamine concentration during intravenous cocaine self-administration in rats. Psychopharmacology 120:10-20.

Woolverton WL, Johnson KM (1992) Neurobiology of cocaine abuse. Trends Pharmacol Sci 13:193-200.

Wu M, Brudzynski SM, Mogenson GJ (1993) Functional interaction of dopamine and glutamate in the nucleus accumbens in the regulation of locomotion. Can J Physiol Pharmacol 71:407-413.

Yokel RA, Pickens R (1974) Drug level of d- and l-amphetamine during intravenous self-administration. Psychopharmacologia 34:255-264.

Zito KA, Vickers G, Roberts DCS (1985) Disruption of cocaine and heroin self-administration following kainic acid lesions of the nucleus accumbens. Pharmacol Biochem Behav 23:1029-1036. 